\title{
Attitudes and beliefs of patients with asthma
}

\author{
P White and G Hewett
}

\section{SUMMARY}

This review summarises current research into patients' attitudes and beliefs about asthma. We found few papers which explore the relationship between findings from qualitative research and measures of diseases process or outcome.

Asthma is widely experienced as a stigmatising, emotionally disturbing and socially restricting disease. There is no single view of asthma that clinicians can learn and apply. Patients' responses to the disease are individual and complex, and the key to understanding patients' attitudes to and beliefs about asthma lies in the recognition of the enormous variation in their responses.

It is clear from current research that the complex interplay of physiological, psychological and social influences which affect patients' attitudes and beliefs are discreet and accessible in individuals and should be brought to bear on the process of the consultation between the patient and the health professional.

$\mathrm{T}$ he aim of this review was to draw together and summarise current evidence from research into patients' attitudes and beliefs about, and experience of, asthma. Much of the research identified is qualitative, and few papers have been found which explore the relationship between findings from qualitative research and measures of the disease process or outcome. The review was carried out by searching the electronic databases Medline, Bids-Embase, Bids-SSSI and BIDS IBSS, and by manual search of three leading respiratory journals and two leading medical sociology journals. The research databases of the National Health Service and the National Asthma Campaign were also examined. A variety of search histories were used including the key words 'adherence', 'attitudes', 'beliefs', 'compliance', 'experience', 'impact', 'morbidity' and 'symptoms'.

\section{EXPERIENCE OF ASTHMA}

Asthma is a disease characterised by unpredictable symptoms. For most patients it is relatively mild although, for some, it leads to hospital admission or even death. ${ }^{1-3}$ There is a broad consensus among health professionals that asthma symptoms can be at least partially prevented or controlled by regular use of inhaled steroids and by high-dose inhaled $\beta_{2}$ agonists during acute attacks in conjunction with short courses of oral steroids. ${ }^{4-6}$ To prevent or relieve attacks quickly, increasing emphasis has been placed on self-management of asthma. ${ }^{7,8}$ In the selfmanagement of asthma, patients are encouraged to react to changing symptoms by changing the dosage and combination of their own drugs. There are few diseases in which the patient is expected to undertake such an active role in determining their own drug regimens. For many asthmatics, these treatment strategies have not succeeded, and rates of morbidity and mortality remain stubbornly high.
As the experience of asthma varies widely, it is not surprising that attitudes and beliefs are also widely differing. Juniper and colleagues ${ }^{9}$ found that, from among symptoms, emotions, environmental factors, physical activities and practical problems, shortness of breath and chest tightness were identified by patients as the two most important aspects of the impact of their asthma. However, breathlessness was perceived to differing extents by different asthmatic patients who had similar impairment of lung function. ${ }^{10-13}$ One effect of these differences is that there is a wide range of perceived usefulness of asthma drugs for similar improvement of lung function. ${ }^{13}$ There is also wide variation in patients' capacity to perceive or detect exacerbations of their asthma and to act early to relieve them. ${ }^{14}$

In a study of the social impact of asthma, Nocon and Booth ${ }^{15}$ explored the everyday experience of asthma and found that asthma had a negative impact 'in employment, schooling, physical activities, social interaction, personal relationships and emotional well-being'. The common experience of stigma in asthma has been described by Snadden and Brown. ${ }^{16}$ More recent qualitative studies of the experience of asthma have reported that many patients at first inquiry state that asthma has little impact on their everyday lives but, on further probing, reveal a catalogue of social restrictions. ${ }^{17,18}$ These include a profound experience of stigma, disruptions to daily life, emotional disturbance and, most important, a diminshed or altered sense of self and personal identity.

The stereotyping of asthmatics as neurotic somatisers which was popular in standard medical texts up to 30 years ago has been replaced by a complex pathophysiological analysis of the impact of asthma and the patient's responses to it. ${ }^{19,20}$ The rejection of the psychological dimension to the experience of asthma has been challenged by Harrison, ${ }^{21}$ who points out that patients who have experienced near fatal attacks or admissions due to asthma are likely to have significant psychosocial morbidity which contributes to asthma presentation through poor adherence to treatment and delay in seeking help. Sibbald and coworkers ${ }^{22}$ observed high levels of psychosocial morbidity among asthmatics in south London, and found a significant correlation between high morbidity and a negative attitude to the disease. They suggest a causal feedback loop between high morbidity and attitude, an hypothesis which is difficult to support as the assessment of morbidity they used may itself reflect elements of attitude.

The range of experience of asthma as a disease should come as no surprise to clinicians involved in its care. However, it is likely that the extent to which asthma is experienced as stigmatising, emotionally disturbing and socially restricting may be disconcerting to many doctors and nurses.
Patrick White

Senior Clinical Lecturer Chronic Illness Group

E-mail:

patrick.white@kcl.ac.com

\section{Graham Hewett}

Research Fellow Multiprofessional Audit Research Group

E-mail: graham.hewett@kcl.ac.com

Department of General Practice and Primary Care, Guy's, King's and St Thomas' School of Medicine, Weston Education Centre, Cutcombe Road, London SE5 9RJ

Correspondence to: Dr P White

Date received: $13 / 05 / 99$ Date accepted: 26/05/99

Asthma in Gen Pract 1999; 7(2): 17-20 


\section{ATTITUDES AND BELIEFS OF ASTHMA AND ITS TREATMENT}

Some asthmatics have difficulty in accepting that they still have asthma despite regular use of asthma drugs. Adams and colleagues ${ }^{18}$ described the challenge which the diagnosis makes to the patient's sense of self as well as the apparent advantage of being able to reject the incorporation of the disease and its treatment into the lifestyle. They proposed classifying asthmatics into three groups - acceptors, deniers, and pragmatists - depending on whether they were ready to accept the identity of asthma sufferer or reject it or, in the last of the three categories, accept the label in part.

Acceptors were more likely than others to state that asthma did not affect their lives, even though their description of its impact was similar to that of the other groups. Asthma had been completely assimilated into these patients' identities ('It's part and parcel of me!'). Hewett reported similar findings among male asthmatics who saw asthma as 'Just a part of me!' ${ }^{17}$ These patients were more likely to be compliant, and to have a good understanding of the disease and of how the medications work.

Adams et al. ${ }^{18}$ further subdivided deniers into 'deniers' and 'distancers', the former claiming not to have asthma at all whereas the latter claimed not to have 'proper asthma'. Proper asthma was seen as much more serious than what these patients experienced. This finding echoed Hewett's earlier study ${ }^{17}$ in which asthmatics reported that they did not have asthma or proper asthma because asthma was 'a state of complete collapse', an experience that most asthmatic patients will never encounter. Similar experiences were reported in Bordeaux. ${ }^{23}$ Hewett in London and Adams et al. in Cardiff all reported a common perception of asthma as a condition and not an illness. ${ }^{17,18}$ Hewett pointed out that seeing asthma as a condition rather than an illness allows the person to come to terms with the condition and to include it into their self-image without accepting the impairment or disability which a chronic illness implies.

However, this view may lead to a reluctance to take treatment and to attribute significant symptoms to the asthma. Adams et al. demonstrated how this can arise: "All wished to avoid membership of what they perceived as a stigmatised group and had reconstructed their asthma in ways that allowed them to deny the label or social identity of "asthmatic".' 18 Viewing their condition as 'bad chests' (interpreted as an acute condition) allowed them to use reliever medication. The use of daily prophylactic medication, however, was not acceptable as that was synonymous with acceptance of being 'asthmatic'.

Pragmatists, according to Adams and colleagues, fell somewhere between the other two types, but were closer to acceptors because they agreed that they had asthma and were taking prophylactic medication. They described two pragmatists who perceived that they had proper asthma, but of the 'acute rather than the chronic type' and that, although they had no objection to taking daily steroids, it was 'not necessary with their type of asthma'. The authors noted of pragmatists: 'All, to varying degrees, were attempting to come to terms with the social identity of "asthmatic" and to reconcile this identity with their other social identities and their self-image. This identity confusion was reflected both in the ways they interpreted their asthma and their self-presentation to others.' The authors concluded that it was not possible to say whether these pragmatic asthmatics would eventually become acceptors or whether their position was relatively stable.

The role of attitudes and beliefs is equally important in children. In one study, more than one-third of the parents of children aged up to 15 years (mean six years) were opposed to inhaler treatment or preferred oral medication, or had a fear of dependence or sideeffects. ${ }^{24}$ Among adolescents, van Es and colleagues ${ }^{25}$ found that their subjects did not use prophylaxis regularly, did not communicate openly with their physicians, and themselves felt that they had inadequate knowledge of their asthma and its treatment.

In a study of high school students and their teachers in Australia, Gibson et al. ${ }^{26}$ also found that young people had a limited knowledge of asthma. They reported that most students considered having an 'internal locus of control' (the degree to which a person believes that their own decisions and actions influence their illness and its effects) important and that this was related to level of knowledge. Students with a strong locus of control were more likely to comply with treatment. These findings are in keeping with a study of adults in California ${ }^{27}$ which showed that reduced perceived control of asthma was associated with increased risk of hospital admission.

Researchers refer frequently to the undertreatment of asthma and, in particular, underuse of preventers and overuse of relievers. ${ }^{28-31}$ These views assume a demonstrable treatment ideal, although such a position is poorly supported by evidence. The terms 'undertreatment', 'underuse' and 'overuse' are usually employed in relation to continuing morbidity, hospital admission or death, and imply a desired level of treatment which is not being achieved. From this, it is not a big step to a culture of blame in which undertreatment or underuse implies some level of negligence or irresponsibility. If patients are not taking the treatment in the way or to the extent that authoritative consensus suggests they should (and if GPs are not prescribing asthma treatment in this way or to this extent), then there is a need to understand why. At the very least, it should be suspected that the prescribed treatments are in some way not entirely suitable in terms of delivery, effectiveness or side-effects.

Britten, ${ }^{32}$ in a study of (non-asthmatic) patients from general practice, found that some patients held a very positive view of medicine, which they saw as having 'magical qualities'. On the other hand, many patients held negative views and were concerned that the longterm effects could be harmful, that they were 'unnatural' or that they impaired the body's own immune system. Some patients were concerned that medicines tended to deal with symptoms rather than the causes of disease while others avoided 'strong medicines', or would only take medicines at the prescribed time if it was deemed important or as and 
when needed rather than as directed. Similar findings have been reported in studies of asthmatics. ${ }^{33}$ Low levels of adherence to inhaled steroid regimens have been found together with discordance between the way in which inhaled steroid use is recommended and the way in which patients actually use them. Regular use of inhaled steroids was positively associated with a good understanding of their mode of action, a feeling of dependency and a positive perception of effectiveness. It was negatively associated with a poor understanding of the mode of action, the experience of severe attacks, side-effects and the feeling that the good effects of the drug had worn off.

Four 'attitude clusters' to medication have been described among asthmatics: dislike of asthma medication; dislike of disability; dislike of public life interference; and dislike of social and emotional interference. ${ }^{34}$ The main components of the dislike of asthma medication involved the delivery system, a general fear of steroids and a fear of taking medications every day.

There is no single patients' view of asthma that clinicians can identify and apply to all patients. Patients' responses to the disease are individual and complex, and require individual consideration by their clinicians.

\section{IMPLICATIONS FOR MANAGEMENT STRATEGIES}

It is likely that attitudes towards, and beliefs about, asthma and its treatment affect both patient and doctor success in disease control. Doctors and patients are likely to have different attitudes and beliefs, which can lead to misunderstanding for the patient and frustration for the clinician. It is not surprising that St Claire and colleagues ${ }^{35}$ found that GPs had a more biomedical model of health than their patients:

'From this [the GPs'] perspective, for asthmatic patients to use their inhalers regularly is logical and crucial. From the asthmatic patients' perspective, however, being able [to do what they want] might matter more. Indeed, regular use of an inhaler might make them feel less 'able' and thus further from health. In other words, non-compliance might be irrational from GPs' but rational from asthmatics' perspective.'

For Christie et al. ${ }^{36}$ the patient's sense of self and identity is an important and neglected part of the management strategy. The management of 'self' is often more important to patients and is sometimes in conflict with the management of asthma:

'Doctors and patients construe health differently, and consequently have different objectives for health care behaviour. Such differences help explain why patients adopt patterns of behaviour which, from the point of view of professionals, seem irrational. The implication is that a process of negotiation based on mutual acknowledgement of perspectives will help GPs and their patients achieve better agreement and compliance with health care regimes.'
In multiple sclerosis, Rothwell et al. ${ }^{37}$ reported that doctors and patients do not agree on perceptions of disability. Their findings are likely to apply equally to asthma. This has important practical implications as became clear in a study of the viewpoints of parents with asthmatic children in which the clinician's failure to listen to their patients' stories led to delays in diagnosis.

Studies of asthma deaths and near-fatal asthma show how important patient beliefs and behaviour are when the consequences of asthma are grave: 'The conclusions from all these studies of asthma deaths suggest that the main problems with preventable asthma deaths in the 1990s are behavioural rather than pharmacotherapeutic.' ${ }^{21}$ Evans argues that clinicians must move towards a partnership with their patients that involves understanding the patient's views and beliefs, reinforcing those that are appropriate and persuading patients to change those which are inappropriate by a combination of educational initiatives and negotiation of shared treatment goals. ${ }^{38}$

The idea of self-management in asthma challenges those doctors and nurses described by Lagerløv et $a l .{ }^{39}$ as the 'I will manage it' types when it comes to the doctor-patient relationship. The term 'selfmanagement' implies a departure from the medical model of chronic illness management in which the patient is the passive recipient of medical care, and fits the sociological concept of the "undiminished self' who has successfully reconciled the social identity of 'asthmatic' with their other social and personal identities. ${ }^{40,41}$ Self-management of asthma arises from a medical perception of passing to the patient the responsibility to increase or decrease medication in response to symptoms to limit the severity of exacerbations and to keep drug use to a necessary minimum. This view is likely to be perplexing to those patients who already regard themselves as managing their own asthma.

\section{CONCLUSIONS}

The key to using our understanding of patients' attitudes towards and beliefs about asthma lies in the recognition of the enormous variation there is in the experience and attitudes of asthmatics. There is no asthma stereotype. All of the research points to a complex interplay of physiological, psychological and social influences. These elements are discrete and accessible in individuals, and should be brought into the process of consultation between the patient and the health professional. Special attention to coexistent psychosocial morbidity should be paid to all asthmatics who have near-fatal attacks or who are admitted to hospital. Asthmatics with low peak expiratory flow (PEF) who report infrequent or minor symptoms require consideration because of the risk of late recognition of severe exacerbations. Convincing such patients of the value of regular prophylaxis may require regular completion of diaries of daily PEF recordings. A nurse or doctor who insists that the diagnosis must be addressed may alienate patients who are actively in denial of the diagnosis of asthma. A working diagnosis of 'wheezy episodes' or similar euphemism may be needed to facilitate the patient's acceptance of 
treatment. Equally, patients' fears of the potential for drug addiction and side-effects may require acknowledgement and acceptance if such patients are to allow even limited prescribing by a health professional. Clinicians must learn to accept the validity of the patient's viewpoint, and be prepared to negotiate the meaning of asthma and treatment goals.

While the attitudes and beliefs of patients are likely to be crucial to how they perceive medical advice and participate in treatment, Kolbe and co-workers ${ }^{42}$ found that the attitudes and beliefs of patients were not predictive of serious management errors in the actions patients took in responding to acute severe asthma (requiring admission to hospital). ${ }^{42}$ Nonetheless, they did find a considerable gap between what patients said they would do and what they actually did.

This last observation should make sense. Beliefs and attitudes are not principles of living; they are the background material which influences our behaviour. Most of us believe in good behaviour, but few of us behave well all the time. The beliefs and attitudes of asthmatics provide the signposts which doctors, nurses and patients themselves should use to direct their relationships and therapeutic advice. Expecting patients to behave strictly according to their beliefs and attitudes is unreasonable. Failure to take account of their beliefs and attitudes is reckless.

\section{References}

1. Marks GB, Burney PGJ, Premaratne UN, et al. Asthma in Greenwich, UK. Impact of the disease and current management practices. Eur Respir J 1997;10:1223-9

2. Campbell MJ, Holgate ST, Johnston SL. Trends in asthma mortality. BMJ 1997;315:1012

3. Hyndman SJ, Williams DRR, Merrill SL, et al. Rates of admission to hospital for asthma. BMJ 1994;308:1596-600

4. British Thoracic Society, The National Asthma Campaign, The Royal College of Physicians of London, et al. The British guidelines on asthma management: 1995 Review and position statement. Thorax 1997;52(Suppl 1):S1-S21

5. Taylor DR, Town GI, Herbison GI, et al. Asthma control during long term treatment with regular inhaled salbutamol and salmeterol. Thorax 1998;53:744-52

6. Walsh LJ, Wong CA, Pringle M, et al. Use of oral corticosteroids in the community and the prevention of secondary osteoporosis: A cross-sectional study. BMJ 1996;313:344-6

7. Baldwin, DR, Pathak, UA, King R, et al. Outcome of asthmatics attending asthma clinics utilising self management plans in general practice. Asthma Gen Pract 1997;5(2):31-2

8. D'Souza WJ, Te KH, Fox C, et al. Long-term reduction in asthma morbidity following an asthma self-management programme. Eur Respir J 1998;11(3):611-6

9. Juniper EF, Guyatt GH, Epstein RS, et al. Evaluation of impairment of health related quality of life in asthma: Development of a questionnaire for use in clinical trials. Thorax 1992;47:76-83

10. Rubinfield AR, Pain MCF. Perception of asthma. Lancet 1976;i:882-4

11. Kendrick AH, Higgs CMB, Whitfield MJ, et al. Accuracy of perception of severity of asthma: Patients treated in general practice. BMJ 1993;307;422-4

12. Fritz GK, McQuaid EL, Spirito A, et al. Symptom perception in pediatric asthma: Relationship to functional morbidity and psychological factors. J Am Acad Child Adolesc Psychiatry 1996;35(8):1033-41

13. Falliers CJ. Ventilatory impairment in asthma: perceptions $v s$ measurements. Chest 1998;113(2):265-7

14. Atherton HA, White PT, Hewett G, et al. Relationship of daytime asthma symptom frequency to morning peak expiratory flow. Eur Respir J 1996;9:232-6

15. Nocon A, Booth T. The social impact of asthma. Fam Pract
1991;8:37-41

16. Snadden D, Brown JB. Asthma and stigma. Fam Pract 1991;8:329-35

17. Hewett G. Just a part of me - Men's reflections on chronic asthma. London: South Bank University, 1994

18. Adams S, Pill R, Jones A. Medication, chronic illness and identity: The perspective of people with asthma. Soc Sci Med 1997;45:189-202

19. Houston JC, Joiner CL, Trounce JR. A short textook of medicine, 2nd edn. London: English University Press, 1966

20. Holgate ST. Asthma: Past, present, and future. Eur Respir J 1993;6:1507-20

21. Harrison BD. Psychosocial aspects of asthma in adults. Thorax 1998;53(6):519-25

22. Sibbald B, White P, Pharoah C, et al. Relationship between psychosocial factors and asthma morbidity. Fam Pract 1988;5:12-7

23. Cousson-Gelie F, Foex C, Gibaud F, et al. The patient's representation of asthma. Preliminary results of a survey. Rev Mal Respir 1998;15(4):513-7

24. Lim SH, Goh DY, Tan AY, et al. Parents' perceptions towards their child's use of inhaled medications for asthma therapy. $J$ Paediatr Child Health 1996;32(4):306-9

25. van Es SM, le Coq EM, Brouwer AI, et al. Adherence-related behavior in adolescents with asthma: Results from focus group interviews. J Asthma 1998;35(8):637-46

26. Gibson PG, Shah S, Mamoon HA. Peer-led asthma education for adolescents: impact evaluation. $J$ Adolesc Health 1998;22(1):66-72

27. Katz PP, Yelin EH, Smith S, et al. Perceived control of asthma: Development and validation of a questionnaire. Am J Respir Crit Care Med 1997;155(2):577-82

28. Kaur B, Anderson HR, Austin J, et al. Prevalence of asthma symptoms, diagnosis, and treatment in 12-14 year old children across Great Britain (international study of asthma and allergies in childhood, ISAAC UK). $B M J$ 1998;316:118-24

29. Pantin C. Is the ratio of inhaled corticosteriod to bronchodilator a good indicator of the quality of asthma prescribing? Cross-sectional study linking prescribing data to data on admissions. BMJ 1996;313:1124-6

30. Parameswaran K, Hildreth AJ, Chadha D, et al. Asthma in the elderly: Underperceived, underdiagnosed and undertreated; a community survey. Respir Med 1998;92(3):573-7

31. Walsh LJ, Wong CA, Cooper S, et al. Morbidity from asthma in relation to a regular treatment: A community-based study. Thorax 1999;54:296-300

32. Britten N. Patient's ideas about medicines: A qualitative study in general practice. Br J Gen Pract 1994;44:465-8

33. Atherton A, Tyrrell Z, White PT. Perception and reported use of inhaled steroids in primary care. Report to the Department of Health. London: Kings College, 1998

34. Osman LM, Russell IT, Friend JAR, et al. Predicting patient attitudes to asthma medication. Thorax 1993;48:827-30

35. St Claire L, Watkins CJ, Billinghurst B. Differences in meanings of health: An exploratory study of general practitioners and their patients. Fam Pract 1996;13(6):511-6

36. Christie MJ, French D, Weatherstone L, et al. The patients' perceptions of chronic disease and its management: psychosomatics, holism and quality of life in contemporary management of childhood asthma. Psychother Psychosom 1991;56:197-203

37. Rothwell PM, McDowell Z, Wong CK, et al. Doctors and patients don't agree: Cross-sectional study of patients' and doctors' perceptions and assessments of disability in multiple sclerosis. BMJ 1997;314:1580-3

38. Evans D. To help patients control asthma the clinician must be a good listener and teacher. Thorax 1993;48:685-7

39. Lagerløv P, Leseth A, Matheson I. The doctor-patient relationship and the management of asthma. Soc Sci Med 1998;47:85-91

40. Memel, D. Chronic disease or physical disability? The role of the general practitioner. Br J Gen Pract 1996;46:109-13

41. Charmaz K. Struggling for a self: Identify levels among the chronically ill. In: Roth JA, Conrad P, eds. Research in the sociology of health care, vol 6. Greenwich: JAI Press, 1987

42. Kolbe J, Vamos M, Fergusson, et al. Determinants of management errors in acute chronic asthma. Thorax 1998;53:14-20 